\title{
A perspective piece on Diabetes Self-Management Education and Support (DSMES) programmes for under-represented groups with T2DM in the UK
}

\author{
MICHELLE HADJICONSTANTINOU, ${ }^{1}$ LAUREN M QUINN ${ }^{2}$ FRANCES TIPPINS, ${ }^{3}$ SALLY SCHREDER, ${ }^{2}$ \\ KAMLESH KHUNTI, ${ }^{1,2}$ MELANIE J DAVIES ${ }^{1,2}$
}

\begin{abstract}
Self-management is critical for optimisation of diabetes care, and diabetes self-management education and support (DSMES) programmes are well recognised to improve biomedical, behavioural and psychological outcomes for people living with diabetes. The aim of this perspective piece is (1) to delineate the barriers experienced by underrepresented groups with type 2 diabetes mellitus (T2DM) and (2) to evaluate the role of targeted interventions and digital health as potential solutions to address these barriers and bridge the gaps in diabetes care. Common barriers to accessing DSMES programmes include practical issues such as timing and location, as well as psychological barriers such as stigma. Available evidence shows that tailoring diabetes self-management programmes to fit with people's culture or specific needs increases effectiveness and acceptability of DSMES programmes in seldom heard groups. Digital-based self-management programmes have the opportunity to reach a vast number of individuals and offer an alternative source to empower people with T2DM. However, technology may also widen health inequalities and increase social isolation. Therefore, further research is required to establish bespoke and effective diabetes self-management programmes for under-represented individuals with T2DM.
\end{abstract}

Br J Diabetes 2021;21:3-10

Key words: self-management, diabetes, education

Diabetes Research Centre, College of Life Sciences, University of Leicester, Leicester, UK

2 Leicester Diabetes Centre, University Hospitals of Leicester NHS Trust, Leicester, UK

3 University Hospitals of Leicester NHS Trust, Leicester, UK

Address for correspondence: Mrs Sally Schreder

Leicester Diabetes Centre, University Hospitals of Leicester NHS Trust, Leicester, LE5 4PW, UK

E-mail: sally.schreder@uhl-tr.nhs.uk

https://doi.org/10.15277/bjd.2021.278

\section{Introduction}

It has been approximately 20 years since the UK's National Service Framework for diabetes declared self-management the cornerstone of effective diabetes care and recognised that self-management can be achieved through the provision of information and psychological support. 'People with diabetes require knowledge, skills and motivation to assess health risks, understand lifestyle behaviours and adopt new health behaviours. ${ }^{1}$ Considering that over $99 \%$ of diabetes care consists of self-management by the individual, diabetes self-management education and support (DSMES) programmes have been recognised as an essential 'tool' to support the people with diabetes to self-care and self-manage effectively. ${ }^{2}$

Evidence supports the effectiveness of DSMES programmes particularly in reducing $\mathrm{HbA}_{1} \mathrm{c}^{3-5}$ and improving cardiovascular outcomes. ${ }^{6}$ Despite these positive outcomes, the number of people with diabetes attending DSMES programmes remains low. The UK's most reliable attendance figures are derived from figures from the National Diabetes Audit (NDA), and the most recent data from 2016-17 shows improvement in both the offering of and attendance to DSMES programmes. ${ }^{7}$ However, barriers to accessing DSMES remain for all people with diabetes, but are even more prevalent for those from under-represented groups, including (but not limited to) individuals from minority ethnic groups or those who have intellectual disability (ID) or severe mental illness (SMI). ${ }^{8}$

Aim

The aim of this perspective piece is firstly to discuss barriers to accessing DSMES programmes, focusing on under-represented groups including minority ethnic groups, people with ID and individuals with SMI. Secondly, we outline the evidence for targeted interventions in these groups and how technology could form a solution to address many of the barriers experienced by these under-represented groups.

\section{Diabetes self-management education and support programmes (DSMES)}

DSMES programmes are essential for all people with diabetes as they aim to promote diabetes knowledge, skills and understanding of how to self-care while also supporting long-lasting behaviour change. ${ }^{9} \mathrm{NICE}$ recommends that all people with type 
Figure 1. National standards for diabetes self-management and structured education programmes. A pictorial representation of the nationally agreed standards expected of all diabetes self-management and support programmes for people with type 2 diabetes in the UK. ${ }^{25,26}$

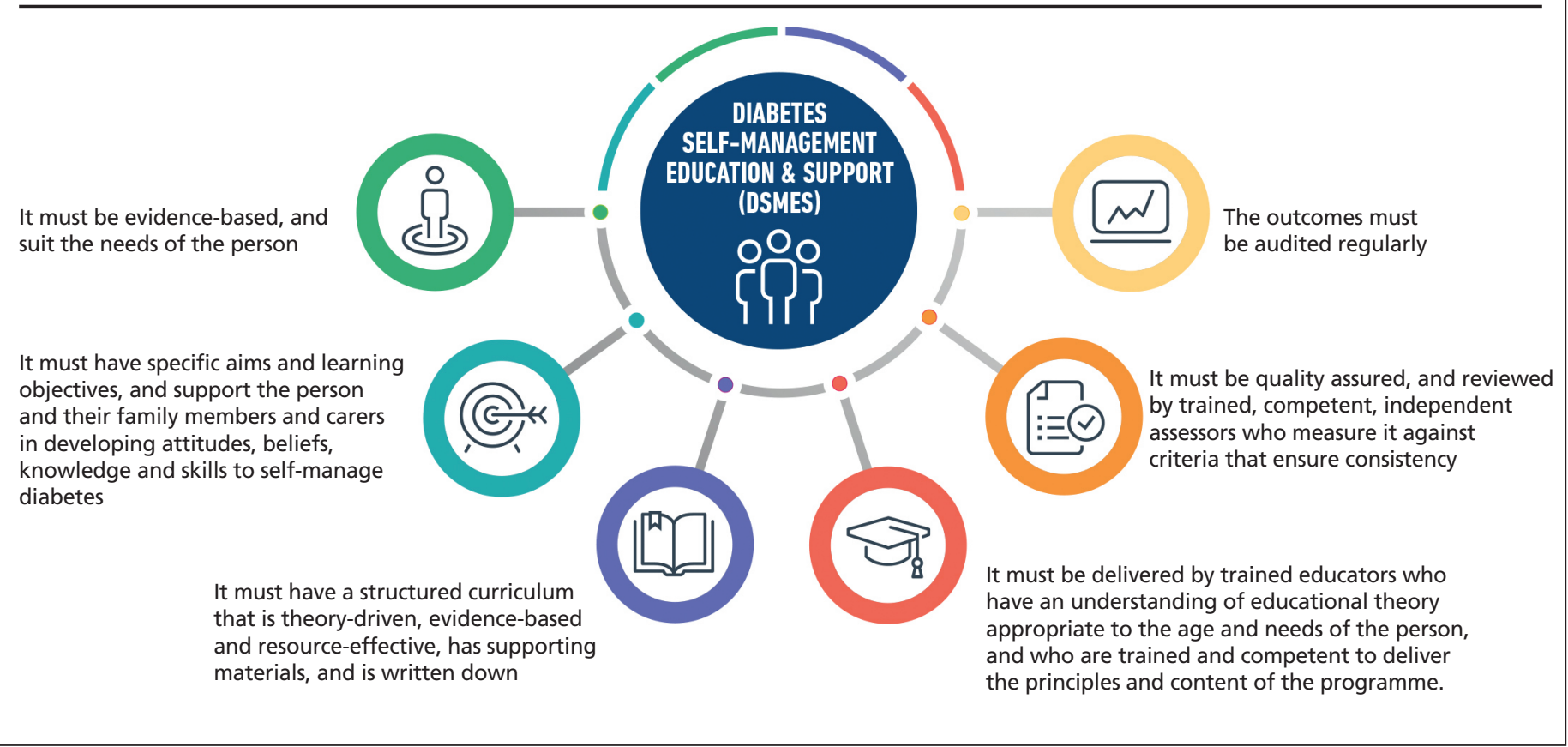

2 diabetes mellitus (T2DM) are offered a structured education programme at the time of diagnosis. ${ }^{10}$

In the UK the recommended standards for all DSMES programmes are as follows: must be evidence-based and patientfocused; comprises a structured curriculum; have clear aims for the person with diabetes and their caregivers to support uptake of positive attitudes, knowledge, skills and health beliefs; must be delivered by trained educators, comprised of a multidisciplinary diabetes care team; must be care quality assured by independent reviewers; and the programme outcomes should be audited frequently to ensure quality of care delivery (Figure 1). ${ }^{10-13}$ Moreover, the UK Medical Research Council Framework recommends patient and public involvement in the curriculum development, design and implementation stage and the intervention should undergo multiple rounds of testing in feasibility studies to randomised controlled trials (RCTs). ${ }^{11}$ The precise format of structured education programmes will vary according to the local population and resources available.

A number of UK face-to-face DSMES programmes meet NICE requirements and are accredited to be offered in the UK. The most well-established DSMES programmes are the X-PERT Diabetes Programme, DESMOND and the Diabetes Manual programme. ${ }^{14-16}$ Although these are the main accredited national programmes available, non-accredited programmes are also provided across local Clinical Commissioning Groups. Such programmes, however, fail to meet NICE requirements and, even though they vary in content and quality, they have not been validated to determine the impact on health behaviour and biomedical outcomes. These programmes differ in format and content, incorporating one-to-one, group-based and telemedicine approaches, but which have not been directly compared in head-to-head analyses. ${ }^{11}$

\section{Effectiveness of DSMES programmes}

The effectiveness of DSMES programmes has been well evidenced over the years in terms of biomedical, behavioural and psychological benefits. A number of high quality publications including a Cochrane review in 2005 demonstrated the effectiveness of group-based training for self-management on fasting blood glucose levels, $\mathrm{HbA}_{1 c}$, diabetes knowledge, systolic blood pressure levels and body weight. ${ }^{17}$

At an international level, DSMES programmes ${ }^{14,15,18}$ have been shown to significantly improve $\mathrm{HbA}_{1 \mathrm{c}}$, body mass index, triglycerides, cholesterol, blood pressure and creatinine. ${ }^{19} \mathrm{How}$ ever, the heterogeneity in study design, education programme structure and outcomes assessed render it difficult to compare and contrast studies, and to delineate the most effective components of education programmes that should be widely adopted. ${ }^{11}$ Focusing on the UK programmes in particular (X-PERT, DESMOND and Diabetes Manual), they have all been shown in RCTs to improve psychosocial outcomes in the short term and the former two showed significant $\mathrm{HbA}_{1 \mathrm{c}}$ reduction also. The DESMOND programme further showed sustained improvements in psychosocial outcomes at three years. ${ }^{20}$

Figure 2 summarises a number of common characteristics across DSMES programmes that were shown to be associated with positive outcomes. Common participant characteristics were also observed: those who showed a greater reduction in 


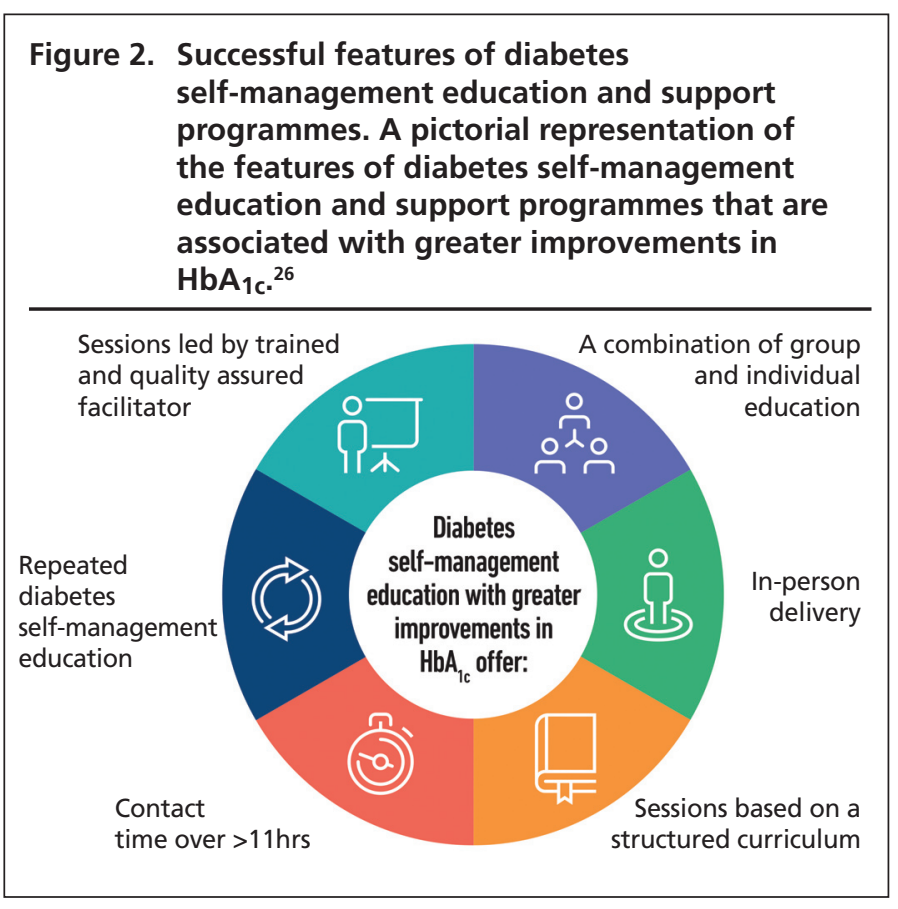

Figure 3. Who benefits the most from diabetes self-management education and support programmes? A pictorial representation of the characteristics of participants that are associated with greater reductions in $\mathrm{HbA}_{1 \mathrm{c}}{ }^{26}$

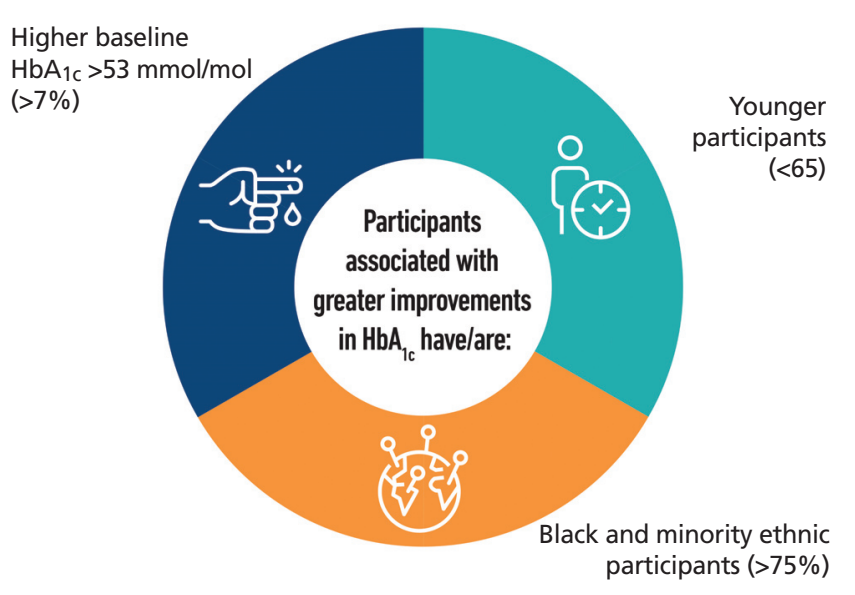

$\mathrm{HbA}_{1}$; those with a higher baseline $\mathrm{HbA}_{1}$; those of a younger population (<65 years); and groups with higher proportions of people from minority ethnic groups (Figure 3).

\section{Barriers to DSMES programmes}

Despite the global availability of DSMES programmes, a number of barriers have been identified that may affect attendance at these programmes. In 2014 and 2017, two systematic reviews summarised a list of reasons for non-attendance. The most common reasons were: (1) issues with timing and/or length of courses; (2) access/transportation issues; (3) family and/or work conflicts; (4) lack of information about the course; (5) lack of information on benefits of attending by healthcare professionals; (6) participants' beliefs that they already had sufficient information to self-manage their condition; and (7) contentment with the information received from their general practitioner or diabetes team. ${ }^{21,22}$

In 2015 the All-Party Parliamentary Group for Diabetes, a nonpartisan cross-party interest group in the UK, published a booklet entitled "Taking Control: Supporting People to Self-Manage their Diabetes". Based on a research study conducted in the region of Cheshire and Merseyside Strategic Clinical Networks, experts and people with type 1 and T2DM identified a number of potential barriers to programme uptake. The list of these barriers was similar to the aforementioned systematic review but also considered additional barriers including: (1) psychological burnout of managing a condition for so long; (2) issues with the use of the term structured 'education' and how it may put off people with diabetes; and (3) shame and stigma associated with the condition, particularly among minority ethnic groups. ${ }^{2}$ The authors reported a large number of referral letters sent by GPs, which consisted of little information about the purpose or benefit of the DSMES programmes. ${ }^{2}$ This lack of engagement by GPs may be a significant contributor to the disparity between recorded referrals and attendance by the National Diabetes Audit. ${ }^{7}$

Poor data collection was identified as an additional barrier to uptake, leading to minimum information about who attended and, more importantly, who did not attend. This limitation to service provision led to the introduction of an electronic referral system. In various South London boroughs electronic referral and booking systems have been introduced along with various other improvements to service which have increased attendance rates. Leading on from this is the development of a toolkit by the Health Innovation Network to optimise delivery and attendance to DSMES. ${ }^{23}$ More recently, a NICE surveillance review 2019 identified the Embedding Diabetes Education RCT as having the potential to inform and change recommendations to improve attendance. ${ }^{24}$ The Embedding Diabetes Education trial is one of the largest and complex trials and has developed an 'embedding toolkit' aiming to address the barriers and enablers to uptake at service user, healthcare professional and organisational level. ${ }^{24}$

\section{Barriers to DSMES in under-represented groups Minority ethnic groups}

The UK represents a richly diverse population with South Asian people (Indian, Pakistani and Bangladeshi) making up the majority of the largest minority. ${ }^{25}$ This subgroup nevertheless has a 2-4 times higher risk of T2DM and develop diabetes on average 5-10 years earlier than their white European counterparts. ${ }^{26-28}$

Additional barriers to accessing high quality diabetes care for minority ethnic groups include communication issues and language differences, migrant status, low socioeconomic status and relatively higher levels of deprivation. ${ }^{29}$ Allory et al found that barriers for deprived people with diabetes included geographical restrictions, lack of promotion of the DSMES programmes, lack of relationships built with their healthcare professionals and lack of support to integrate with a new community within the DSMES programme. ${ }^{30}$ 
The UK HEAL-D study evaluated barriers to diabetes education in Afro-Caribbean people with diabetes through focus groups and qualitative analysis. They reported that, although Afro-Caribbean individuals were motivated to manage their diabetes and prevent diabetes-related complications, they would benefit from tailored information around diet, physical activity and weight loss related to their lifestyles. Sociocultural barriers to diabetes management included acceptance within their culture of increased body size and rejection of body mass index, combined with lack of social opportunities to undertake physical activity. Therefore, culturally appropriate education interventions aimed at Afro-Caribbean groups with diabetes should consider these findings. ${ }^{31}$

For Bangladeshi people with diabetes in the UK, Greenhalgh et al similarly showed this community were motivated to manage their diabetes but semi-structured interviews revealed that barriers were structural, linguistic and cultural in nature. Importantly, they experienced knowledge gaps in diet, exercise and cause of diabetes, 32 which could be addressed through culturally appropriate DSMES programmes.

The mainstream UK diabetes education programmes are designed for the majority, and therefore do not address the specific learning needs for members of minority ethnic groups. This has led to increased trials of culturally tailored education programmes incorporating community and church members. ${ }^{29}$ Culturally appropriate health education for T2DM in minority ethnic groups including African Americans and South Asians may be a way to achieve improved outcomes, particularly in $\mathrm{HbA}_{1 c}$, total cholesterol and knowledge..$^{33}$

A meta-analysis by Pillay et $a^{\beta}{ }^{3}$ found that DSMES programmes led to greater reductions in $\mathrm{HbA}_{1 \mathrm{c}}$ in minority persons (subgroups with $>75 \%$ non-white participants) compared with majority white groups; differences were also noted in baseline glycaemic control with minority subgroup $\mathrm{HbA}_{1 \mathrm{c}}$ level $13.1 \mathrm{mmol} / \mathrm{mol}(1.2 \%)$ higher than the white majority subgroup. ${ }^{3}$ Despite clear evidence illustrating the benefits of DSMES programmes, engagement with this population can be difficult, particularly if programmes fail to consider potential cultural, contextual and linguistic aspects.

A systematic review by Hawthorne et al compared RCTs with structured education targeted at minority ethnic groups and showed that, despite wide heterogeneity between studies, $\mathrm{HbA}_{1 \mathrm{c}}$ significantly improved at 3 and 6 months and diabetes knowledge scores improved at 6 months. Importantly, culturally appropriate diabetes education was superior to mainstream education. ${ }^{29}$ Attridge et al performed a Cochrane review of RCTs $(n=7,453)$ and a meta-analysis ( $n=28$ trials) showing that $\mathrm{HbA}_{1 \mathrm{c}}$ significantly improved at 3 and 6 months in culturally appropriate structured education compared with usual education; $\mathrm{HbA}_{1 \mathrm{c}}$ improvement was sustained to a lesser extent up to 12 and 24 months following the intervention. Improvement in lipids was not sustained beyond 3 months and the diabetes knowledge score improved at 3 and 12 months. ${ }^{33}$ Zeh et al further supported these findings, outlining that culturally appropriate DSMES programmes, which address cultural, language, religious and health literacy differences, led to improvements in a range of patient-reported outcome measures. However, the deemed cultural competency of these education programmes varies widely, accounting for differences in the benefits observed. ${ }^{34}$

For Muslim people with diabetes, Ramadan presents additional challenges to their diabetes management and care. The importance of structured education to help people with diabetes optimise management of their diabetes during Ramadan is recognised by the European Association for the Study of Diabetes (EASD) and American Diabetes Association (ADA) guidelines, and structured education which incorporates community awareness packages has been shown to be effective at reducing hypoglycaemia. ${ }^{35}$

Given the degree of heterogeneity present between studies evaluating culturally competent diabetes education, delineating the most effective elements of these programmes has been challenging. However, Jain et al reported on the role of peer-educators in health education for minority ethnic groups, including the observed benefits and flexibility of this approach. ${ }^{36}$ Similarly, Alzubaidi et al supported this finding for Arabic people with diabetes. ${ }^{37}$ It is equally important to acknowledge that cultural adaptation of interventions should not be homogenous but rather individualised to each minority ethnic group and adapted to the given cultural context. Culturally adapted programmes in the UK include DESMOND $\mathrm{BME}^{38}$ and DoSA (Diabetes for South Asians). ${ }^{39}$

\section{Diabetes and intellectual disability (ID)}

According to data from the National Diabetes Audit 2016-17, the prevalence of ID is around $40 \%$ higher in people with diabetes compared with the general population, and $90 \%$ of people registered with ID and diabetes have T2DM. ${ }^{7}$ Self-management of T2DM can present significant challenges for this population due to socioeconomic inequalities, ${ }^{40}$ limited support worker knowledge ${ }^{41}$ and poor living arrangements which contribute to a sedentary lifestyle. ${ }^{42}$ Health services further contribute to the situation by failing to make reasonable adjustments that take account of, and respond to, the cognitive and communication impairments experienced by many of this population.

A systematic review by MacRae et al explored self-management in people with ID and found that they wanted to learn more about their condition, and similarly that their caregivers lacked knowledge and did not feel able to provide diabetes management advice. ${ }^{43}$ Furthermore, a qualitative study by Brown et a ${ }^{14}$ identified from structured interviews that increasing access, improving communication and providing resources adapted to people with T2DM and ID were key to improving diabetes care. Maine et al performed semi-structured interviews in people with T2DM and ID, providing additional insight into how self-management education should be targeted; key themes that arose focused on enhancing diabetes knowledge, tailoring strategies for ID, ensuring autonomy, removing stigma, self-care and incorporating feedback from caregivers. ${ }^{45}$ Trip et al also focused on the importance of educating caregivers to help further support service users. ${ }^{46}$ Another systematic review by Maine et al, which included 23 RCTs, outlined that diabetes education for people with ID needed to align with their needs, be widely accessible, ensure appropriate resources were available and provide adequate social support in order to improve illness perception and self-efficacy. ${ }^{47}$

Health literacy is an additional barrier to diabetes education. For 
example, Osborne et al showed that limited health literacy was indirectly associated with suboptimal glycaemic control and reduced diabetes self-care behaviours, and this was attributed to inadequate social support for individuals with lower health literacy. This is an important finding because it demonstrates that health literacy does not need to be a barrier to optimising diabetes management. ${ }^{48}$

The DESMOND ID programme ${ }^{49}$ was the first study to adapt and pilot a national structured self-management programme for adults with ID and T2DM. In a pilot study, the DESMOND ID intervention was found to be both acceptable and feasible, and led to a small significant improvement in $\mathrm{HbA}_{1 \mathrm{c}}$ but with a wide confidence interval. Following this, the STOP education programme, which was specifically designed for individuals with T2DM and ID, also passed feasibility testing, demonstrated benefits for service users and care givers alike, and is currently undergoing a RCT. ${ }^{50}$ Given the early stages of these education interventions for people with T2DM and ID, this reflects the need for further research to deliver more patient-centred and effective DSMES programmes for this at-risk group.

\section{Diabetes and severe mental illness (SMI)}

People with SMI (including schizophrenia, bipolar and major depressive disorder) experience poorer outcomes and are twice as likely to develop T2DM than those without SMI. ${ }^{51}$ Diabetes selfmanagement is considered important in this population, as people with SMI often feel disempowered to self-manage their diabetes.

El-Mallakh et al interviewed people with T2DM and schizophrenia and found that psychotic symptoms were significant barriers to diabetes self-care behaviours and that self-management education needed to focus on helping individuals to manage their mental ill health, whilst accommodating for their diabetes as well. ${ }^{52}$ These findings were further supported by Blixen et al who showed that people with SMI were exposed to significant stress and stigma, lacked social support and experienced fragmentation of care; it was recommended that all three of these factors needed addressing, and interventions should focus on the diabetes and the mental ill health in combination to help support self-care behaviours. ${ }^{53}$

The STEPWISE RCT targeted people with T2DM and schizophrenia, schizoaffective disorder or first-episode psychosis $(n=414)$ and found that, although there was no improvement in biomedical or psychological outcomes and it was not cost-effective, participants valued the educational intervention and participant retention was good. ${ }^{54}$ However, the study recognised that significantly greater resources and funding were required when delivering education programmes in this cohort. Another RCT evaluating a stigmacoping and empowerment intervention in people with schizophrenia or depression observed significant improvement in psychological outcomes, including quality of life, functioning and compliance, but did not significantly differ from the usual care arm..$^{55} \mathrm{~A}$ systematic review performed by Cimo et al in people with T2DM and schizophrenia highlighted the importance of diet and exercise advice, with a focus on cognition, motivation and discussion around weight management, particularly with antipsychotic therapies..$^{56}$ On the other hand, Fenton et al undertook an RCT evaluating a 12 -week education prevention programme and found significant improvements in weight, waist circumference, $\mathrm{HbA}_{1 \mathrm{c}}$ and blood pressure; however, this study also included people with prediabetes. ${ }^{57}$ A 2016 Cochrane review evaluating the effects of DSMES interventions for people with SMI suggested that the evidence remains insufficient as to whether these types of interventions improve outcomes. In this review, small improvements in BMI and weight post intervention, and improved diabetes knowledge and self-efficacy were observed. Despite the positive outcomes, we must acknowledge the main limitation of this review - the inclusion of only one RCT with a small sample size. This limitation highlights the need for further research into the real impact of self-management programmes in those with existing mental health conditions. $^{51}$

\section{Role of digital online self-management programmes for T2DM}

Health technology has evolved over the last two decades and sources such as digital self-management programmes are now used as supplementary and/or stand-alone sources for knowledge and emotional/social support in the management of chronic conditions. ${ }^{58-61}$ Indeed, an incline in the adoption of digital health education has been observed during the coronavirus pandemic and our group have previously reported on the value of digital health in diabetes care and self-management. ${ }^{60}$

Despite the rise of digital DSMES programmes, evaluation of this form of support reveals equivocal results; some studies report improvements solely on biomedical outcomes, such as $\mathrm{HbA}_{1 c}$, while other studies report improvements in psychological outcomes. ${ }^{64}$ However, the evidence on psychological outcomes remains scarce, with recent systematic reviews presenting conflicting results and suggesting no significant difference in outcomes such as diabetes-related distress and depression. Woolley et al performed a review of reviews to evaluate online education in diabetes management and, although direct comparisons were challenging due to study heterogeneity, they showed varying degrees of improvement in biomedical, psychosocial and self-efficacy outcomes, with particular benefits observed in diabetes knowledge and social support following online diabetes education. ${ }^{65}$

The first of several digital self-management programmes for people with T2DM in the UK was a multicentre RCT in primary care (HeLP-Diabetes), which showed significant but modest changes in $\mathrm{HbA}_{1 \mathrm{c}}$ but no difference in change in distress scores between the two randomised groups at 12 months. The intervention was widely accepted by participants and met the high recruitment targets. The findings from this trial support the role of digital programmes to increase overall access and uptake to diabetes self-management education. ${ }^{58}$ Barriers associated with face-to-face DSMES programmes are often easier to address with digital programmes, as users have the opportunity to access and read material at their own time and pace.

Digital health interventions similarly need to address the barriers and be culturally appropriate for under-represented groups with T2DM. A review by Doshi et al summarised the evidence for telemedicine in various vulnerable groups with T2DM, but the interventions often combined in-person and telehealth strategies 


\section{Key messages}

- DSMES programmes are proven to be an effective and cost-effective part of diabetes care. However, many complex barriers are faced in relation to attending these programmes, including practical issues such as transport and immobility as well as psychological barriers such as shame and stigma

- Digital self-management programmes could have the potential to increase overall access and uptake to DSMES programmes; however, attention is needed when developing digital self-management programmes to ensure that all sociodemographic groups are included, minimising the possibility of digital inequality and social isolation

- Culturally appropriate health education for T2DM in minority ethnic groups may be a way to achieve improved outcomes

- Currently, DSMES programmes are becoming available for under-represented groups including those with SMI, ID and for ethnic minority groups. Digital-based self-management programmes have the opportunity to reach a vast number of individuals and offer an alternative source to empower people with T2DM

rendering it difficult to ascertain what led to biomedical benefits. ${ }^{66}$

Despite the promise of digital health as a long-term, cost-effective solution in diabetes education and care, ${ }^{67}$ it is however important to acknowledge that people with diabetes who belong to a subgroup are still individuals and therefore preferences within subgroups may vary with other factors. For example, Woolley et al showed that age and educational attainment were the best predictors of diabetes education style preference, highlighting the importance of patient-centred diabetes education. ${ }^{68}$ Digital health may also present additional barriers to minority groups such as individuals who do not own smart phones or have internet access. Furthermore, some may struggle to gain access or use the information provided due to low levels of health literacy. ${ }^{69}$ Therefore, digital health should be considered as one of many solutions to diabetes education for minority and high-risk groups.

\section{Summary and recommendations}

We have outlined the importance and theory behind self-management education and support for people with T2DM. We have also outlined the landscape in the UK for the well-established diabetes education programmes. We have explored the fundamental barriers faced by all people with T2DM in accessing diabetes education, and this is important to address because we are not meeting NICE guideline standards for structured education uptake in the UK. However, of particular concern are the additional barriers to accessing diabetes education for minority groups - including minority ethnic groups, ID and SMI - all of whom are at greater risk of diabetes and have poorer diabetes management compared with the general population. Barriers prevalent in these minority groups centre around culturally insensitive education programmes that inadvertently may widen diabetes knowledge gaps and are not sufficiently inclusive. Education programmes which specifically target the minority individual ethnic groups are beneficial, but can be resource-intensive and further evidence is warranted to identify the relative improvements in biomedical, psychosocial and behavioural outcomes in the short and longer term. The coronavirus pandemic has presented an opportunity to increase the accessibility of diabetes education, particularly through online education programmes; however, the same barriers for minority ethnic groups remain. The evidence to support culturally appropriate DSMES is already lagging behind mainstream DSMES, hence there is an opportunity to focus attention on culturally appropriate digital health from the outset. The best way to address these barriers is to integrate relevant patients and the public in the design stages of the education programme. Furthermore, further research is needed to elucidate the cultural differences and sensitive ways to address norms that do not align with optimisation of diabetes self-management.

Acknowledgement The authors acknowledge support from the National Institute for Health Research (NIHR) Applied Research Collaboration East Midlands (NIHR ARC-EM), the NIHR Leicester Biomedical Research Centre (BRC), which is a partnership between University Hospitals of Leicester NHS Trust, Loughborough University and the University of Leicester.

Conflict of interest We do not hold any conflicts of interest, however, for transparency we provide the following statement of conflict: MJD is the Principal Investigator on the DESMOND programme (Diabetes education and self-management for people with newly diagnosed T2DM). LQ, SS and FT are employed by the University Hospitals of Leicester NHS Trust, which receives not-for-profit income for DESMOND. All authors are actively engaged in research and have previously received grants for DESMOND from NIHR, MRC and Diabetes UK to develop and test Diabetes Self-Management Education and Support programmes like DESMOND. The University Hospitals of Leicester (UHL) NHS Trust (for which LQ, SS and FT have a contract) receives licensing fees to support implementation of the DESMOND programme in CCGs in the UK, Ireland and Australia.

Author contributorship MH \& LQ are joint lead authors. MH, LQ, FT and SS led the development of the manuscript. MH, LQ, FT, SS, KK and MJD revised the content and structure of the manuscript. All authors read and approved the final manuscript.

\section{Funding None.}

\section{References}

1. Department of Health. National service framework for diabetes: standards. 2001, 1-45 [cited 2019 Mar 20]. Available from: https://assets. publishing.service.gov.uk/government/uploads/system/uploads/

2. All-Party Parliamentary Group. Taking control: supporting people to selfmanage their diabetes 2015 [cited 2019 Mar 12]. Available from: https://jdrf.org.uk/wp-content/uploads/2015/10/APPG-Diabetes-ReportEducation-Final-Report.pdf

3. Pillay J, Armstrong MJ, Butalia S, et al. Behavioral programs for type 2 diabetes mellitus: a systematic review and network meta-analysis. Ann Intern Med 2015;163(11):848-60. https://doi.org/10.7326/M15-1400

4. Odgers-Jewell K, Ball LE, Kelly JT, Isenring EA, Reidlinger DP, Thomas R. Effectiveness of group-based self-management education for individuals with type 2 diabetes: a systematic review with meta-analyses and metaregression. Diabet Med 2017;34(8):1027-39. https://doi.org/10.1111/ dme. 13340 
5. Zhao FF, Suhonen R, Koskinen S, Leino-Kilpi $\mathrm{H}$. Theory-based self-management educational interventions on patients with type 2 diabetes: a systematic review and meta-analysis of randomized controlled trials. J Adv Nurs 2017;73(4):812-33. https://doi.org/10.1111/jan.13163

6. He X, Li J, Wang B, et al. Diabetes self-management education reduces risk of all-cause mortality in type 2 diabetes patients: a systematic review and meta-analysis. Endocrine 2017;55(3):712-31. https://doi.org/ 10.1007/s12020-016-1168-2

7. NHS Digital. National Diabetes Audit, 2016-17. Report 1: Care processes and treatment. 2018 [cited 2019 Mar 28]. Available from: https://www.hqip.org.uk/wp-content/uploads/2018/03/National-Diabetes-Audit-2016-17-Report-1-Care-Processes-and-Treatment-T....pdf

8. Majeed-Ariss R, Jackson C, Knapp P, Cheater FM. A systematic review of research into black and ethnic minority patients' views on self-management of type 2 diabetes. Health Expect 2015;18(5):625-42. https://doi.org/10.1111/hex.12080

9. Beck J, Greenwood DA, Blanton L, et al. 2017 National Standards for Diabetes Self-Management Education and Support. Diabetes Care 2017; 40(10):1409-19. https://doi.org/10.2337/dci17-0025

10. NICE. T2DM in adults: management 2015 [cited 2019 Feb 27]. Available from: https://www.nice.org.uk/guidance/ng28

11. Chatterjee S, Davies MJ, Heller S, Speight J, Snoek FJ, Khunti K. Diabetes structured self-management education programmes: a narrative review and current innovations. Lancet Diabetes Endocrinol 2018;6(2):130-42. https://doi.org/10.1016/S2213-8587(17)30239-5

12. Department of Health and Diabetes UK. Structured Patient Education in Diabetes: Report from the Patient Education Working Group. 2005. [cited 2019 Feb 27]. Available from: https://webarchive.nationalarchives.gov.uk/20130105204013/http://www.dh.gov.uk/en/Publicationsandstatistics/Publications/PublicationsPolicyAndGuidance/DH_4113 195

13. Davies MJ, D'Alessio DA, Fradkin J, et al. Management of Hyperglycemia in Type 2 Diabetes, 2018. A Consensus Report by the American Diabetes Association (ADA) and the European Association for the Study of Diabetes (EASD). Diabetes Care 2018;41(12):2669-701. https://doi.org/ 10.2337/dci18-0033

14. Davies MJ, Heller S, Skinner T, et al. Effectiveness of the diabetes education and self management for ongoing and newly diagnosed (DESMOND) programme for people with newly diagnosed type 2 diabetes: cluster randomised controlled trial. BMJ 2008;336(7642):491-5. https://doi.org/10.1136/bmj.39474.922025.BE

15. Deakin T, Cade J, Williams R, Greenwood D. Structured patient education: the Diabetes X-PERT Programme makes a difference. Diabet Med 2006:23(9):944-54. https://doi.org/10.1111/j.1464-5491.2006.01906.x

16. Successful Diabetes. The Diabetes Manual Structured Education Programme for Type 2 Diabetes: 'One-to-One, All-in-One' 2020 [cited 2019 Feb 27]. Available from: http://www.successfuldiabetes.com/workingwith-diabetes/diabetes-manual

17. Deakin T, McShane CE, Cade JE, Williams RD. Group based training for self-management strategies in people with type 2 diabetes mellitus. Cochrane Database Syst Rev 2005(2):CD003417. https://doi.org/ 10.1002/14651858.CD003417.pub2

18. Diabetes UK. Getting more of your patients on diabetes education courses 2018 [cited 2019 May 24]. Available from: https://cdn.shopify.com/s/files/1/1922/6045/files/1419_Taking_control_H $C P$ resource_V8.pdf

19. Miselli $V$, Trento M, Porta M. Group care for type 2 diabetes: the Turin experience. Diabetes Spectrum 2012;25(2):79-84. https://doi.org/ 10.2337/diaspect.25.2.79

20. Khunti K, Gray L, Skinner T, et al. Effectiveness of a diabetes education and self management programme (DESMOND) for people with newly diagnosed type 2 diabetes mellitus: three year follow-up of a cluster randomised controlled trial in primary care. BMJ 2012;344:e2333. https://doi.org/10.1136/bmj.e2333

21. Lawal M. Barriers to attendance in diabetes education centres: a systematic review. Diabetes Primary Care 2014;16:299-306.

22. Horigan G, Davies M, Findlay-White F, Chaney D, Coates V. Reasons why patients referred to diabetes education programmes choose not to attend: a systematic review. Diabet Med 2017;34(1):14-26. https://doi.org/10.1111/dme.13120
23. London SCN/Health Innovation Network South London. Structured education for type 2 diabetes: a toolkit for optimal delivery. 2018 [cited 2018 May 24]. Available from: https://healthinnovationnetwork.com/resources/type-2-diabetes-a-toolkit-for-optimal-delivery-of-structured-education/

24. ISRCTN Registry. Embedding diabetes education [cited 2019 Jun 25]. Available from: http://www.isrctn.com/ISRCTN21321635

25. Office of National Statistics. Census Analysis: Ethnicity and Religion 2011 [cited 2019 Apr 18]. Available from: https://www.ons.gov.uk/peoplepopulationandcommunity/culturalidentity/ethnicity/articles/2011 censusanaly sisethnicityandreligionofthenonukbornpopulationinenglandandwales/2015-06-18

26. Sattar N, Gill JM. Type 2 diabetes in migrant south Asians: mechanisms, mitigation, and management. Lancet Diabetes Endocrinol 2015; 3(12):1004-16. https://doi.org/10.1016/S2213-8587(15)00326-5

27. Khunti K, Camosso-Stefinovic J, Carey M, Davies MJ, Stone MA. Educational interventions for migrant South Asians with type 2 diabetes: a systematic review. Diabet Med 2008;25(8):985-92. https://doi.org/ 10.1111/j.1464-5491.2008.02512.x

28. Bhurji N, Javer J, Gasevic D, Khan NA. Improving management of type 2 diabetes in South Asian patients: a systematic review of intervention studies. BMJ Open 2016;6(4):e008986. https://doi.org/10.1136/ bmjopen-2015-008986

29. Hawthorne K, Robles Y, Cannings-John R, Edwards AG. Culturally appropriate health education for type 2 diabetes in ethnic minority groups: a systematic and narrative review of randomized controlled trials. Diabet Med 2010;27(6):613-23. https://doi.org/10.1111/j.14645491.2010.02954.x

30. Allory E, Lucas $\mathrm{H}$, Maury A, et al. Perspectives of deprived patients on diabetes self-management programmes delivered by the local primary care team: a qualitative study on facilitators and barriers for participation in France. BMC Health Serv Res 2020;20(1):855. https://doi.org/ 10.1186/s12913-020-05715-3

31. Moore AP, Rivas CA, Stanton-Fay S, Harding S, Goff LM. Designing the Healthy Eating and Active Lifestyles for Diabetes (HEAL-D) self-management and support programme for UK African and Caribbean communities: a culturally tailored, complex intervention under-pinned by behaviour change theory. BMC Public Health 2019;19(1):1146. https://doi.org/10.1186/s12889-019-7411-z

32. Greenhalgh T, Helman C, Chowdhury AM. Health beliefs and folk models of diabetes in British Bangladeshis: a qualitative study. BMJ 1998;316(7136):978. https://doi.org/10.1136/bmj.316.7136.978

33. Attridge $M$, Creamer J, Ramsden M, Cannings-John R, Hawthorne K. Culturally appropriate health education for people in ethnic minority groups with type 2 diabetes mellitus. Cochrane Database Syst Rev 2014(9). https://doi.org/10.1002/14651858.CD006424.pub3

34. Zeh P, Sandhu HK, Cannaby AM, Sturt JA. The impact of culturally competent diabetes care interventions for improving diabetes-related outcomes in ethnic minority groups: a systematic review. Diabet Med 2012:29(10):1237-52. https://10.1111/j.1464-5491.2012.03701.x

35. Ibrahim M, Davies MJ, Ahmad E, et al. Recommendations for management of diabetes during Ramadan: update 2020, applying the principles of the ADA/EASD consensus. BMJ Open Diabetes Res Care 2020;8(1):e001248. https://doi.org/10.1136/bmjdrc-2020-001248

36. Jain N. Increasing Black, Asian and Minority Ethnic (BAME) patient and community awareness - using the peer educator model. J Renal Care 2014;40(S1):36-40. https://doi.org/10.1111/jorc.12089

37. Alzubaidi H, Mc Namara K, Browning C. Time to question diabetes selfmanagement support for Arabic-speaking migrants: exploring a new model of care. Diabet Med 2017;34(3):348-55. https://doi.org/10.1111/ dme.13286

38. DESMOND BME. DESMOND Cultural Adaptation 2019 [cited 2019 May 28]. Available from: https://www.desmond-project.org.uk/portfolio/ desmond-cultural-adaptation/

39. Successful Diabetes. DoSA: T2DM Education Programme for South Asians, 2019 [cited 2019 May 28]. Available from: http://www.successfuldiabetes.com/living-with-diabetes/dosa-type-2-diabetes-educationprogramme-for-south-asians

40. Emerson $E$, Baines $S$. Health inequalities and people with learning disabilities in the UK. Tizard Learning Disability Review 2011;16(1):42-8. 
https://doi.org/10.5042/tldr.2011.0008

41. Cardol M, Rijken M, van Schrojenstein Lantman-de Valk H. Attitudes and dilemmas of caregivers supporting people with intellectual disabilities who have diabetes. Patient Educ Couns 2012;87(3):383-8. https://doi.org/10.1016/j.pec.2011.11.010

42. Melville CA, Cooper SA, Morrison J, et al. The prevalence and incidence of mental ill-health in adults with autism and intellectual disabilities. $J$ Autism Dev Disord 2008;38(9):1676-88. https://doi.org/10.1007/ s10803-008-0549-7

43. MacRae S, Brown M, Karatzias T, et al. Diabetes in people with intellectual disabilities: a systematic review of the literature. Res Dev Disabil 2015;47:352-74. https://doi.org/10.1016/j.ridd.2015.10.003

44. Brown M, Taggart L, Karatzias T, et al. Improving diabetes care for people with intellectual disabilities: a qualitative study exploring the perceptions and experiences of professionals in diabetes and intellectual disability services. J Intellect Disabil Res 2017;61(5):435-49. https://doi.org/10.1111/jir.12369

45. Maine A, Brown M, Dickson A, Truesdale M. The experience of type 2 diabetes self-management in adults with intellectual disabilities and their caregivers: a review of the literature using meta-aggregative synthesis and an appraisal of rigor. J Intellect Disabil 2020;24(2):253-67. https://doi.org/10.1177/1744629518774172

46. Trip H, Conder J, Hale L, Whitehead L. The role of key workers in supporting people with intellectual disability in the self-management of their diabetes: a qualitative New Zealand study. Health Soc Care Community 2016;24(6):789-98. https://doi.org/10.1111/hsc.12262

47. Maine A, Brown MJ, Dickson A, Truesdale M. An evaluation of mainstream type 2 diabetes educational programmes in relation to the needs of people with intellectual disabilities: a systematic review of the literature. J App/ Res Intellect Disabil 2019;32(2):256-79. https://doi.org/ 10.1111/jar.12544

48. Osborn CY, Bains SS, Egede LE. Health literacy, diabetes self-care, and glycemic control in adults with type 2 diabetes. Diabetes Technol Ther 2010;12(11):913-19. https://doi.org/10.1089/dia.2010.0058

49. Taggart L, Truesdale M, Carey ME, et al. Pilot feasibility study examining a structured self-management diabetes education programme, DESMOND-ID, targeting $\mathrm{HbA}(1 \mathrm{c})$ in adults with intellectual disabilities. Diabet Med 2018;35(1):137-46. https://doi.org/10.1111/dme.13539

50. Dunkley AJ, Tyrer F, Gray LJ, et al. Type 2 diabetes and glucose intolerance in a population with intellectual disabilities: the STOP diabetes cross-sectional screening study. J Intellect Disabil Res 2017;61(7):66881. https://doi.org/10.1111/jir.12380

51. McBain H, Mulligan K, Haddad M, Flood C, Jones J, Simpson A. Self management interventions for T2DM in adult people with severe mental illness. Cochrane Database Syst Rev 2016;4:CD011361. https://doi.org/ 10.1002/14651858.CD011361.pub2

52. El-Mallakh P. Evolving self-care in individuals with schizophrenia and diabetes mellitus. Arch Psychiatr Nurs 2006;20(2):55-64. https://doi.org/ 10.1016/j.apnu.2005.09.002

53. Blixen CE, Kanuch S, Perzynski AT, Thomas C, Dawson NV, Sajatovic M. Barriers to self-management of serious mental illness and diabetes. Am J Health Behav 2016:40(2):194-204. https://doi.org/10.5993/ AJHB.40.2.4

54. Holt RIG, Gossage-Worrall R, Hind D, et al. Structured lifestyle education for people with schizophrenia, schizoaffective disorder and first-episode psychosis (STEPWISE): randomised controlled trial. $\mathrm{Br} J$ Psychiatry 2019;214(2):63-73. https://doi.org/10.1192/bjp.2018.167
55. Gaebel W, Zäske H, Hesse K, et al. Promoting stigma coping and empowerment in patients with schizophrenia and depression: results of a cluster-RCT. Eur Arch Psychiatry Clin Neurosci 2020;270(5):501-11. https://doi.org/10.1007/s00406-019-01064-3

56. Cimo A, Dewa CS. Symptoms of mental illness and their impact on managing type 2 diabetes in adults. Can J Diabetes 2018;42(4):37281. https://doi.org/10.1016/j.jcjd.2017.08.256

57. Fenton A, Sharps P, Kverno K, RachBeisel J, Gorth M. A 12-week evidence-based education project to reduce cardiovascular and metabolic risk in adults with serious mental illness in the integrated care setting. J Am Psychiatr Nurses Assoc 2020:1078390320902825. https://doi.org/ $10.1177 / 1078390320902825$

58. Murray E, Sweeting $M$, Dack $C$, et al. Web-based self-management support for people with type 2 diabetes (HeLP-Diabetes): randomised controlled trial in English primary care. BMJ Open 2017;7(9):e016009. https://doi.org/10.1136/bmjopen-2017-016009

59. Tan SS, Goonawardene N. Internet health information seeking and the patient-physician relationship: a systematic review. J Med Internet Res 2017;19(1):e9. https://doi.org/10.2196/jmir.5729

60. Quinn LM, Davies MJ, Hadjiconstantinou M. (2020). Virtual consultations and the role of technology during the COVID-19 pandemic for people with type 2 diabetes: the UK perspective. J Med Internet Res 2020;22(8):e21609. https://doi.org/10.2196/21609

61. Greenwood DA, Gee PM, Fatkin KJ, Peeples M. A systematic review of reviews evaluating technology-enabled diabetes self-management education and support. J Diabetes Sci Technol 2017;11(5):1015-27. https://doi.org/10.1177/1932296817713506

62. Nobis S, Lehr D, Ebert DD, et al. Efficacy of a web-based intervention with mobile phone support in treating depressive symptoms in adults with type 1 and type 2 diabetes: a randomized controlled trial. Diabetes Care 2015;38(5):776-83. https://doi.org/10.1186/1471-244X-13-306

63. Pal K, Eastwood SV, Farmer A, et al. Computer-based interventions to improve self-management in adults with type 2 diabetes: a systematic review and meta-analysis. Diabetes Care 2014;37:1759-66. https://doi.org/10.2337/dc13-1386

64. Hadjiconstantinou M, Byrne J, Bodicoat DH, et al. Do web-based interventions improve well-being in type 2 diabetes? A systematic review and meta-analysis. J Med Internet Res 2016;18(10):e270. https://doi.org/10.2196/jmir.5991

65. Woolley AK, Hadjiconstantinou M, Davies M, Khunti K, Seidu S. Online patient education interventions in type 2 diabetes or cardiovascular disease: a systematic review of systematic reviews. Prim Care Diabetes 2019;13(1):16-27. https://doi.org/10.1016/j.pcd.2018.07.011

66. Doshi R, Aseltine RH, Sabina AB, Graham GN. Interventions to improve management of chronic conditions among racial and ethnic minorities. J Racial Ethn Health Disparities 2017;4(6):1033-41. https://doi.org/ 10.1007/s40615-017-0431-4

67. Hedman E. Therapist guided internet delivered cognitive behavioural therapy. BMJ 2014;348:g1977. https://doi.org/10.1136/bmj.g1977

68. Woolley AK, Chudasama Y, Seidu SI, et al. Influence of sociodemographic characteristics on the preferred format of health education delivery in individuals with type 2 diabetes mellitus and or cardiovascular disease: a questionnaire study. Diabet Med 2020;37(6):982-90. https://doi.org/10.1111/dme.14275

69. Hsu J, Huang J, Kinsman J, et al. Use of e-health services between 1999 and 2002: a growing digital divide. JAMIA 2005;12(2):164-71. https://doi.org/10.1197/jamia.M1672 